\title{
Study of Risk Factors Associated with Suicide Attempt in Patients with Bipolar Disorder Type I
}

\author{
Nivedhitha Selvakumar ${ }^{2}$ \\ ${ }^{1}$ Department of Psychiatry, Mahatma Gandhi Medical College and \\ Research Institute, Sri Balaji Vidyapeeth (Deemed-to-be University), \\ 2Department of Psychiatry, JIPMER, Puducherry, India \\ ${ }^{3}$ Department of Psychiatry and NDDTC, All India Institute of Medical \\ Sciences, New Delhi, India \\ ${ }^{4}$ Department of Psychiatry, Sri Lakshmi Narayana Institute of \\ Medical Sciences, Puducherry, India
}

Karthick Subramanian ${ }^{1}$ Vikas Menon ${ }^{2}$ Siddharth Sarkar ${ }^{3}$ Vigneshvar Chandrasekaran

\begin{abstract}
Address for correspondence Karthick Subramanian, MD, Department of Psychiatry, Mahatma Gandhi Medical College and Research Institute, Sri Balaji Vidyapeeth (Deemed-to-be University), Pillayarkuppam, Puducherry 607403, India (e-mail: drkarthick.psy@gmail.com).
\end{abstract}

J Neurosci Rural Pract 2020;11:291-298

\section{Keywords \\ - bipolar \\ - coping skills \\ - course \\ - outcome \\ - suicide \\ - India}

Background Suicide is the leading contributor to mortality in bipolar disorder (BD). A history of suicidal attempt is a robust predictive marker for future suicide attempts. Personality profiles and coping strategies are the areas of contemporary research in bipolar suicides apart from clinical and demographic risk factors. However, similar research in developing countries is rarer.

Objectives The present study aimed to identify the risk factors associated with suicidal attempts in BD type I (BD-I).

Materials and Methods Patients with BD-I currently in clinical remission ( $N=102)$ were recruited. Sociodemographic details and the clinical data were collected using a semistructured pro forma. The psychiatric diagnoses were confirmed using the Mini-International Neuropsychiatric Interview 5.0. The National Institute of Mental Health-Life Chart Methodology Clinician Retrospective Chart was used to chart the illness course. Presumptive Stressful Life Events Scale, Coping Strategies Inventory Short Form, Buss-Perry aggression questionnaire, Past Feelings and Acts of Violence, and Barratt Impulsivity scale were used to assess the patient's stress scores, coping skills, aggression, violence, and impulsivity, respectively.

Statistical Analysis Descriptive statistics were used for demographic details and characteristics of the illness course. Binary logistic regression analyses were performed to identify the predictors for lifetime suicide attempt in BD-I.

Results A total of 102 patients (males $=49$ and females $=53$ ) with BD-I were included. Thirty-seven subjects (36.3\%) had a history of suicide attempt. The illness course in suicide attempters more frequently had an index episode of depression, was encumbered with frequent mood episodes, especially in depression, and had a higher propensity for psychiatric comorbidities. On binary logistic regression analysis, the odds ratios (ORs) for predicting a suicide attempt were highest for positive family history of suicide (OR: $13.65,95 \%$ confidence interval $[\mathrm{Cl}]: 1.28-145.38, p=0.030$ ), followed by the presence of an index depressive episode (OR: $6.88,95 \% \mathrm{Cl}: 1.70-27.91, p=0.007)$, and lower scores on problem-focused disengagement (OR: $0.72,95 \% \mathrm{Cl}: 0.56-0.92, p=0.009$ ).
DOI https://doi.org/

10.1055/s-0040-1709347

ISSN 0976-3147.
License terms

(이 (1) $\Theta \circledast$ 
Conclusion BD-I patients with lifetime suicide attempt differ from non-attempters on various course-related and temperamental factors. However, an index episode depression, family history of suicide, and lower problem-focused engagement can predict lifetime suicide attempt in patients with BD-I.

\section{Introduction}

\section{Burden of Suicide and Nonsuicidal Self-Harm}

Every year, more than 800,000 people succumb to suicide, which accounts for $1.4 \%$ of global death rates. The problem of suicide remains a major public health concern as suicide remains the second most common cause of death in young adults aged 15 to 24 years. ${ }^{1}$ For each suicidal death, there are 20 to 30 suicide attempts which remain undetected. ${ }^{2}$ Suicidal behaviors are more prominent in bipolar disorder (BD) when compared with other major psychiatric illnesses. Suicidal behavior in BD confers a greater risk of mortality compared with that seen in the general population. ${ }^{3}$ Recent research has furthered our understanding on the risk factors and warning signs for suicidal behavior in BD. ${ }^{4}$

\section{Risk Factors for Suicide}

Multiple risk factors are at play, which interact with one another and culminate in an increased vulnerability for suicidal behaviors. The major risk factors are genetic, ${ }^{5}$ psychological, sociocultural, and personal experiences of trauma and loss. ${ }^{67}$ The interactions of such factors support the theoretical models of stress-diathesis and gene-environment epigenetic modulation. ${ }^{8,9}$ In addition, factors specific to bipolar illness course contribute to the increased risk of suicide in patients with BD.

Earlier studies highlighted that the illness course of BD was comparable across suicide attempters and nonattempters. ${ }^{10}$ However, recent studies have teased out the risk factors related to the illness course such as recent affective episodes with depressive polarity, ${ }^{11,12}$ an illness course clustered predominantly with depressive episodes, ${ }^{11-14}$ index episode depression or mixed, younger age at onset, and multiple hospitalizations. ${ }^{11,15}$

Temperamental factors such as high harm avoidance, high novelty seeking, and low self-directedness are associated with an elevated suicide risk in BD. ${ }^{16-20}$ Personality traits such as impulsivity, aggression, and violence can impart greater suicidal risk in BD. ${ }^{21-23}$ Some studies point out that cluster C (anxious and avoidant) traits can underlie frequent suicide attempts. ${ }^{24}$ Such psychological attributes are considered as endophenotypes in suicide behavior. ${ }^{25}$ Other risk factors may include the presence of stressful life events, which can lead to suicidal behavior. ${ }^{26,27}$ Comorbidities such as anxiety disorders and substance use disorders also increase the suicide risk in patients with BD. ${ }^{11}$

\section{Evidence from Developing Countries}

Studies from the developing nations in Southeast Asia reveal that the suicide rates vary from 0.43 to $331 / 100,000$ which is comparatively higher than the global average. ${ }^{28}$ The psychiatric morbidity was observed in $58 \%$ of suicidal deaths and $45 \%$ in nonfatal suicidal behaviors in low- and middle-income countries (LMICs). ${ }^{29}$ Mood disorders comprised the majority of patients in both suicide and nonfatal suicidal behaviors with depression being the most common ranging from 22 to $59.7 \%{ }^{29,30}$ The quality appraisal of studies on suicide in the LMICs revealed them to be of lower quality due to less consistency in defining suicide and nonsuicidal self-injuries. ${ }^{28,29,31}$

Indian studies on suicide revealed rates up to 82 to $95 / 100,000$ especially in the rural population and in southern India. 32,33 The studies further revealed that suicide rates were higher in younger women with hanging and organophosphorus pesticide consumption as the common methods. Lower socioeconomic status, alcohol abuse, and interpersonal issues were associated with suicide in India. ${ }^{32}$ Contrasting with western and Southeast Asian literature on suicide, depression was noted in only $3.8 \%$ of the suicides in India and was associated with alcohol use disorders, financial and interpersonal issues..$^{33}$ Concisely stating, the prevalence, methods, psychiatric morbidity, and risk factors for suicide in LMICs differed from the western population and thus adding value for undertaking the current study in a developing nation such as India.

Identification of the risk factors associated with suicide attempt in BD can assist us in identifying the subgroups with elevated risk of morbidity and mortality. ${ }^{34}$ The present study aimed to identify the risk factors associated with lifetime suicide attempt in patients with BD type I (BD-I).

\section{Materials and Methods}

\section{Setting}

The study was conducted in the outpatient department of psychiatry in a tertiary teaching cum hospital in southern India. The hospital provides subsidized medical services to a population hailing mostly from the low socioeconomic strata. Monthly follow-up clinics are conducted for patients diagnosed with mood disorders.

\section{Participants}

The patients who had a diagnosis of BD-I, as confirmed with Mini-International Neuropsychiatric Interview (MINI 5.0),35 aged 18 to 65 years, with minimum illness duration of at least 3 years, were included. As the study involved application of self-report scales, only patients who were in remission were considered. Patients who scored less than 8 in Hamilton Depression Rating Scale, 17 -item version ${ }^{36}$ and less than 7 in Young Mania Rating Scale ${ }^{37}$ were considered to be in clinical remission. 


\section{Scales Used}

Mini-International Neuropsychiatric Interview $5.0^{35}$

The MINI is a short structured diagnostic interview administered by the clinician, used to screen as well as confirm the presence of various psychiatric disorders. The instrument allows for diagnosing comorbidities including substance use disorders. The screening instrument typically takes 15 to 30 minutes for administration. The reliability and validity of MINI are comparable with standard interview instruments such as the Structured Clinical Interview for DSM and the Composite International Diagnostic Interview. The screening instrument is applied for all the participants and those who answer "yes" for an item in the instrument will be assessed further in detail with the corresponding module in MINI.

\section{National Institute of Mental Health-Life Chart Methodology ${ }^{38}$}

The National Institute of Mental Health-Life Chart Methodology Clinician Retrospective Chart (NIMH-LCM-CRC) is a clinician-administered instrument, which assists in charting the illness course with depiction of various types of mood episodes along with their characteristics (episode number, duration, and interepisodic interval). The charting commences with the index episode and proceeds along each episode. The instrument also allows for coding the medications and life events along the illness course. The illness course of the study participants until the present visit was depicted in the NIMH-LCM-CRC.

\section{Presumptive Stressful Life Events Scale ${ }^{39}$}

The presumptive stressful life events scale (PSLES) is an Indian adaptation of the extensively used Holmes-Rahe scale. The scale is used to assess for the common stressful life events, which are encountered by the patients in the past year. The scale comprises items, which are relevant to the sociocultural context, and hence the same has been widely used in the Indian research. The patients were asked to recall those stressful events which they had encountered in the past year and tick those items in PSLES.

\section{Coping Strategies Inventory Short Form ${ }^{40}$}

The instrument is used to assess the coping skills of an individual when presented with a problem. The original Coping Strategies Inventory (CSI) (78-item) was shortened to a 16-item version: CSI-Short Form (SF). The individual either confronts the problem at hand (engagement) or avoids dealing with the problem (disengagement). The confrontation and avoidance can be of either emotion-focused type or the problem-focused type. Thus, the scale yields four subscale scores. The patients were asked to recall how they usually dealt with problematic situations in their life and select the best suited response to the items.

\section{Beck's Hopelessness Scale ${ }^{41}$}

The Beck's Hopelessness Scale is a widely used self-rated instrument to assess for hopelessness, a proximal risk factor for suicide attempt. The scale consists of 20 items, with "true" or "false" answers. Some of the items are reverse scored. The patients were advised to select the best option which reflected their present state of mind. Hopelessness can be gauged as none or minimal (0-3), mild (4-8), moderate (9-14), or severe with definite suicide risk (15+).

\section{Past Feelings and Acts of Violence ${ }^{42}$}

The Past Feelings and Acts of Violence-SF consists of 12 items, and was developed from the 36-item Feelings and Acts of Violence Scale. The scale has good reliability (Cronbach $\alpha=$ 0.77 ) and validity. The items focus on the dimensions of anger and the overt actions resulting from the same. The response options are "never," "sometimes," "often," or "very often." Two questions are answered as "never," "once," "twice," or "more than twice." One question has the option of yes/no. Higher scores indicate that the patient can become violent quite easily.

\section{Buss-Perry Aggression Questionnaire ${ }^{43}$}

The Buss-Perry aggression questionnaire is a self-report scale with 29 items. The scale gives the degree of aggression in four factors (physical aggression, verbal aggression, anger, and hostility). Each question is answered on a Likert scale of 1 (extremely uncharacteristic of me) to 7 (extremely characteristic of me). Higher scores indicate severe degrees of aggressive temperament. The patients were asked to administer the scale themselves providing honest answers that reflect their usual self.

\section{Barratt Impulsivity Scale ${ }^{44}$}

The Barratt impulsivity scale is one of the most widely used self-report scales to measure the degree of impulsivity. Three factors (attentional impulsiveness, motor impulsiveness, and nonplanning impulsiveness) are derived from the questionnaire, which consists of 30 items. Higher the scores in each factor represent the severity of impulsivity in those factors.

\section{Global Assessment of Functioning ${ }^{45}$}

The Global Assessment of Functioning scale is used to score the social, occupational, and psychological functioning of individuals with psychiatric illness. The scores range from 1 (severely impaired) to 100 (extremely high functioning), with increasing scores implying better functioning. The investigator rated the patients' functioning based on the caregiver's report and case records.

\section{Study Procedure}

After inclusion into the study, the sociodemographic details and patient characteristics are entered in a semistructured pro forma. The MINI was used for confirmation of the diagnosis of BD-I and associated comorbid psychiatric conditions. The information is collected from the patient, the key informant (who was with the patient during and in between the episodes), and the medical case records. The illness course was charted in the NIMH-LCM. The patient would then complete the self-report scales. The primary investigator would do clarifications on the content. Written informed consent 
was obtained from all the study participants. The study protocol had prior approval from the Institute Ethics Committee.

\section{Statistical Analysis}

Data was analyzed using SPSS version 16 (SPSS Inc., Chicago, Illinois, United States). Normality of data was assessed by the Shapiro-Wilk's test. For continuous variables, we computed means and standard deviations or median with interquartile range depending on the distribution. Categorical variables were represented as frequencies and percentages. Continuous variables between the groups (those with and without suicide attempt) were compared using the Student's $t$-test or the Mann-Whitney's $U$-test. Discontinuous variables were compared using the chi-square test. Binary logistic regression analysis was used to identify the risk factors associated with suicide attempt in BD-I.

\section{Results}

\section{Baseline Demographic Characteristics}

The mean age of the sample was $35.7( \pm 10.2)$ years (age range: $19-59$ years). Males constituted slightly less than half of the sample ( $n=49,48.0 \%)$. The demographic factors were comparable between the two groups (BD-I subjects with and without a lifetime history of suicide attempt) ( - Table $\mathbf{1})$.

\section{Clinical Characteristics}

The two groups differed significantly with respect to some clinical variables. Notably, higher rates of psychiatric comorbidity were found among the group with lifetime history of attempted suicide. A positive family history of suicide was also more common in this group. Those with a lifetime attempt history had significantly higher number of lifetime mood episodes, more index episodes of depressive polarity, longer average duration of depressive episodes, spent a greater percentage of their illness career in depression, and had a greater number of lifetime mixed episodes. The lifetime suicide attempters also experienced more stressful life events in the past 1 year when compared with those without such a history (-Table 1). Significantly higher levels of emotion-focused disengagement coping style as well as lower levels of problem-focused engagement and disengagement were noted in the group with lifetime suicide attempt. This group also demonstrated significantly higher levels of verbal aggression and hostility (-Table $\mathbf{1}$ ). We did not find any significant differences between the two groups based on comorbid substance use disorder. The two groups did not differ based on impulsivity, violence, and global functioning.

\section{Regression Analysis}

Binary logistic regression analysis was performed to identify predictors of suicide attempt in BD-I. The covariates were selected based on the findings of the aforementioned univariate analysis and those with $p$-value $<0.025$ were selected for inclusion into the logistic regression model. Five covariates were thus selected (-Table 2). Of these, having an index episode of depressive polarity, a positive family history of suicide, and lower scores on problem-focused disengagement emerged as independent predictors of suicide among BD-I subjects. The Nagelkerke $\mathrm{R}^{2}$ of the model was 0.408 indicating that this model predicted $40.8 \%$ of variance in the outcome variable. The Hosmer-Lemeshow's goodnessof-fit statistic was not significant $(p=0.408)$ for the model and hence, acceptable.

\section{Discussion}

The present study attempted to elucidate the illness course-related and individual-related risk factors for attempting suicide in patients with BD-I. Of the 102 patients, 35 patients attempted suicide at least once in their lifetime. The prevalence rate of suicide in the study sample is comparable with the extant literature. ${ }^{15}$ Our findings reiterate that suicide rates in BD may not differ across gender. ${ }^{46,47}$

The suicide attempters differed from the nonattempters in certain illness-related characteristics such as: patient had index episode as depression, spending more time being ill, especially in depression, and encountered a higher number of stressful life events similar to existing literature. ${ }^{14,15,46}$ The attempters and nonattempters had similar age at onset of illness, which contrasts with previous studies, which indicate suicide attempts are associated with an early age at onset of illness. $^{48}$

We included systematic assessment of psychiatric comorbidities in this study when compared with previous similar research from our setting. 49,50 Comorbid anxiety disorders are found to impart significant suicide risk in BD-I patients, ${ }^{15}$ especially panic and generalized anxiety disorders. Substance use disorders did not increase the risk of attempted suicide in the study sample, concurring with some of the previous studies, ${ }^{8,51}$ though other studies have found a clear association between attempted suicide and substance use disorders. ${ }^{14,46}$

The present study could not identify any difference in the trait impulsivity between suicide attempters and nonattempters. This is in line with previous literature, which has found that impulsivity may not differ between suicide attempters and nonattempters who have a diagnosis of BD but differ in those with a diagnosis of major depression. ${ }^{52}$ Though previous studies have found that trait impulsivity is higher in patients who have suicidal behavior than those without. ${ }^{22.53}$ The difference could possibly be due to the low sample size of the present study.

Bipolar patients with suicide attempts have been found to have fewer reasons to live and increased aggression compared with nonattempters but did not differ in impulsivity..$^{54}$ Patients with BD who were religious were found to have lesser lifetime suicidal attempts, aggression, substance use, and history of child abuse compared with nonreligious individuals. ${ }^{55}$ Nonsuicidal self-harm (NSSH) was found to be associated with depression, psychosis, hopelessness, and low self-esteem in pediatric bipolar patients. ${ }^{56}$

\section{Predictors for Lifetime Suicide Attempt}

The present study has revealed that, among various sociodemographic and clinical characteristics, the following could predict a lifetime suicide attempt in BD-I patients: an index 
Table 1 Baseline sample characteristics

\begin{tabular}{|c|c|c|c|}
\hline Parameter & $\begin{array}{l}\text { BD with lifetime suicide } \\
\text { attempt }(N=37)\end{array}$ & $\begin{array}{l}\text { BD with no lifetime suicide } \\
\text { attempt }(N=65)\end{array}$ & Test statistic ( $p$-value) \\
\hline Age & $35.57(9.85)$ & $35.72(10.45)$ & $t=0.074(0.941)$ \\
\hline Gender (males) & $16(43.2 \%)$ & $33(50.8 \%)$ & $\Psi=0.535(0.465)$ \\
\hline \multicolumn{4}{|l|}{ Residence } \\
\hline Rural & 20 & 35 & \multirow[t]{3}{*}{$\Psi=0.492(0.782)$} \\
\hline Urban & 10 & 20 & \\
\hline Semi-urban & 7 & 9 & \\
\hline \multicolumn{4}{|l|}{ Education } \\
\hline Illiterate & 2 & 1 & \multirow[t]{4}{*}{$\Psi=5.840(0.120)$} \\
\hline Primary & 14 & 35 & \\
\hline High school & 12 & 10 & \\
\hline Graduate & 9 & 19 & \\
\hline \multicolumn{4}{|l|}{ Marital status } \\
\hline Single & 10 & 19 & \multirow[t]{5}{*}{$\Psi=3.000(0.558)$} \\
\hline Married & 21 & 42 & \\
\hline Divorced & 1 & 1 & \\
\hline Separated & 4 & 2 & \\
\hline Widow(er) & 1 & 1 & \\
\hline \multicolumn{4}{|l|}{ Family } \\
\hline Nuclear & 36 & 62 & \multirow[t]{3}{*}{$\Psi=0.589(0.745)$} \\
\hline Extended & 0 & 1 & \\
\hline Joint & 1 & 2 & \\
\hline \multicolumn{4}{|l|}{ Occupation } \\
\hline Employed & 17 & 40 & \multirow[t]{3}{*}{$\Psi=2.380(0.304)$} \\
\hline Student & 15 & 18 & \\
\hline Unemployed & 5 & 7 & \\
\hline \multicolumn{4}{|l|}{ SUD comorbidity } \\
\hline Alcohol & 2 & 5 & \multirow[t]{3}{*}{$\Psi=4.417(0.352)$} \\
\hline Nicotine & 5 & 18 & \\
\hline None & 24 & 30 & \\
\hline \multicolumn{4}{|l|}{ Psychiatric comorbidity } \\
\hline Anxiety NOS & 15 & 9 & \multirow[t]{5}{*}{$\Psi=12.539(0.014)^{\mathrm{a}}$} \\
\hline OCD & 1 & 1 & \\
\hline Panic disorder & 1 & 1 & \\
\hline GAD & 1 & 0 & \\
\hline None & 19 & 54 & \\
\hline \multicolumn{4}{|l|}{ Family history } \\
\hline BPAD & 11 & 11 & \multirow[t]{3}{*}{$\Psi=3.860(0.145)$} \\
\hline Psychosis NOS & 2 & 1 & \\
\hline None & 24 & 53 & \\
\hline \multicolumn{4}{|l|}{ Family history of suicide attempt } \\
\hline Yes & 6 & 1 & \multirow[t]{2}{*}{$\Psi=7.947(0.005)^{\mathrm{a}}$} \\
\hline No & 31 & 64 & \\
\hline Age of onset (in y) & $22.86(5.97)$ & $25.17(9.38)$ & $t=1.345(0.182)$ \\
\hline Total duration of illness (mo) & $152.43(94.14)$ & $131.08(95.11)$ & $U=1,019.500(0.202)$ \\
\hline Months of active illness & $19.03(13.11)$ & $13.44(7.01)$ & $U=925.000(0.053)^{a}$ \\
\hline
\end{tabular}


Table 1 (continued)

\begin{tabular}{|c|c|c|c|}
\hline Parameter & $\begin{array}{l}\text { BD with lifetime suicide } \\
\text { attempt }(N=37)\end{array}$ & $\begin{array}{l}\text { BD with no lifetime suicide } \\
\text { attempt }(N=65)\end{array}$ & Test statistic ( $p$-value) \\
\hline Number of mood episodes & $7.05(6.40)$ & $4.32(2.62)$ & $U=893.500(0.029)^{a}$ \\
\hline $\begin{array}{l}\text { Percentage of time spent in } \\
\text { mania }\end{array}$ & $10.47(10.01)$ & $18.29(35.19)$ & $U=935.000(0.096)$ \\
\hline $\begin{array}{l}\text { Percentage of time spent in } \\
\text { depression }\end{array}$ & $4.01(5.77)$ & $2.15(4.40)$ & $U=878.000(0.024)^{a}$ \\
\hline Average duration of mania (mo) & $3.18(1.20)$ & $3.46(0.94)$ & $U=952.500(0.081)$ \\
\hline $\begin{array}{l}\text { Average duration of depression } \\
(\mathrm{mo})\end{array}$ & $1.75(1.75)$ & $1.02(1.50)$ & $U=910.000(0.027)^{\mathrm{a}}$ \\
\hline \multicolumn{4}{|l|}{ Index episode depression } \\
\hline Yes & 9 & 5 & \multirow[t]{2}{*}{$\Psi=5.508(0.019)^{\mathrm{a}}$} \\
\hline No & 28 & 60 & \\
\hline Number of mixed episodes & $0.70(2.83)$ & $0.09(0.42)$ & $U=1,046.500(0.044)^{a}$ \\
\hline Total PSLES score (past 1 y) & $2.22(1.42)$ & $1.42(1.37)$ & $t=2.806(0.006)^{\mathrm{a}}$ \\
\hline GAF score & $83.30(11.10)$ & $85.89(13.88)$ & $t=0.974(0.333)$ \\
\hline \multicolumn{4}{|l|}{ CSI-SF score } \\
\hline PFE & $12.78(2.53)$ & $13.82(2.08)$ & $t=2.222(0.029)^{\mathrm{a}}$ \\
\hline PFD & $12.51(2.33)$ & $14.06(1.85)$ & $t=3.699(0.001)^{\mathrm{a}}$ \\
\hline EFE & $11.35(1.55)$ & $11.82(1.65)$ & $t=1.397(0.166)$ \\
\hline EFD & $10.84(3.02)$ & $9.47(2.67)$ & $t=2.366(0.020)^{\mathrm{a}}$ \\
\hline PFAV score & $14.95(2.15)$ & $14.55(2.81)$ & $t=0.736(0.464)$ \\
\hline \multicolumn{4}{|l|}{ Buss-Perry scale scores } \\
\hline Physical & $23.86(6.37)$ & $24.00(5.85)$ & $t=0.111(0.912)$ \\
\hline Verbal & $16.49(4.62)$ & $14.53(4.60)$ & $t=2.054(0.043)^{\mathrm{a}}$ \\
\hline Anger & $21.31(5.81)$ & $19.87(5.52)$ & $t=1.235(0.220)$ \\
\hline Hostility & $15.86(6.75)$ & $13.15(5.12)$ & $t=2.265(0.026)^{\mathrm{a}}$ \\
\hline \multicolumn{4}{|l|}{ BIS scores } \\
\hline Attentional & $16.49(3.18)$ & $15.74(3.15)$ & $t=1.150(0.253)$ \\
\hline Motor & $20.32(3.93)$ & $20.03(3.55)$ & $t=0.386(0.700)$ \\
\hline Nonplan & $28.78(3.75)$ & $27.97(4.01)$ & $t=1.010(0.315)$ \\
\hline
\end{tabular}

Abbreviations: BD, bipolar disorder; BIS, Barratt impulsivity scale; BPAD, bipolar affective disorder; CSI-SF, Coping Strategies Inventory Short Form; EFD, emotion-focused disengagement; EFE, emotion-focused engagement; GAD, generalized anxiety disorder; GAF, Global Assessment of Functioning; NOS, not otherwise specified; OCD, obsessive-compulsive disorder; PFAV, past feelings and acts of violence scale; PFD, problem-focused disengagement; PFE, problem-focused engagement; PSLES, presumptive stressful life events scale; SUD, substance use disorder.

Note: Values expressed as mean (standard deviation) or frequency (\%); tests employed-Student's $t$-test $(t)$; chi-square test $(\Psi)$; Mann-Whitney's $U$ test $(U)$.

aSignificant at $p<0.05$.

Table 2 Summary of binary logistic regression analysis

\begin{tabular}{|l|l|l|l|}
\hline Variable & Odds ratio & $95 \% \mathrm{Cl}$ & $p$-Value \\
\hline Psychiatric comorbidity & 2.70 & $0.91-7.97$ & 0.072 \\
\hline CSI-SF PFD score & 0.72 & $0.56-0.92$ & $0.009^{\mathrm{a}}$ \\
\hline Family history of suicide & 13.65 & $1.28-145.38$ & $0.030^{\mathrm{a}}$ \\
\hline Total PSLES score & 1.33 & $0.92-1.91$ & 0.129 \\
\hline Index episode depression & 6.88 & $1.70-27.91$ & $0.007^{\mathrm{a}}$ \\
\hline
\end{tabular}

Abbreviations: CSI-SF, Coping Strategies Inventory Short Form; PFD, problem-focused disengagement; PSLES, presumptive stressful life events scale. Note: Outcome variable-BD-I with lifetime suicide attempt (yes/no).

asignificant at $p<0.05$. 
episode of depressive polarity, a positive family history of suicide, and lower scores on problem focused disengagement. A recent meta-analysis supports the view that a positive family history of suicide imparts greater suicide risk in the offspring, ${ }^{11}$ though conflicting reports exist. ${ }^{51}$

\section{Behavioral Interventions for Suicide}

Psychological interventions such as dialectical behavioral therapy, cognitive, and mentalization-based behavioral therapies have been found to be effective in preventing suicide in adults and adolescents..$^{5-59}$ Cognitive behavioral therapy has been found to reduce both repeated suicidal attempts and NSSH behaviors. ${ }^{60}$ Other therapies such as emotion regulation group therapy and dynamic deconstructive psychotherapy have been found to be effective, though evidence is limited. ${ }^{61}$ Behavioral interventions which addressed the suicidal ideas directly were found to have effects posttreatment as well as in long term indicating the need to discuss suicidal ideations on evaluation. ${ }^{62}$

Due to limited resources in developing countries and LMICs, there is a need to involve nonconventional mental health providers such as community organizations, social workers, teachers, and even traditional healers. Hence, evaluation of clinical predictors of suicide could be helpful in training of the above individuals in providing mental health care and crisis intervention. Strategies to reduce accessibility of pesticides such as usage of locked boxes carry validity in Southeast Asia where ingestion of pesticides is quite common. ${ }^{63}$

\section{Limitations}

We did not assess for the presence of psychotic symptoms during the course of illness and the effect of medications when other studies had reported that attempters and nonattempters differed along these variables. ${ }^{24}$ Also, evaluation of characteristics such as intentionality, lethality, and inimicality could have provided more insights regarding suicidal behaviors in BD-I. Other limitations are a low sample size and the selection of patients from the hospital setting alone.

\section{Conclusion}

Among patients with BD-I, the suicide attempters and the nonattempters differ between each other along certain clinical parameters. The BD-I patients with lifetime history of suicide attempt are more likely to have an illness course with index depressive episode, family history of suicide, and low problem-focused disengagement. Future studies, with a longitudinal study design and a larger sample size, are required to replicate the study findings.

\section{Note}

Institutional Review Board approval was obtained and the research work conforms to the Declaration of Helsinki.

\section{Funding}

None.

\section{Conflict of Interest}

None declared.

\section{References}

1 WHO. Suicide data [Internet]. WHO. [Cited January 29, 2020.] Available at: http://www.who.int/mental_health/prevention/ suicide/suicideprevent/en. Accessed January 29, 2020

2 Wasserman D, Suicide: An Unnecessary Death. London: CRC Press; 2001

3 Chen YW, Dilsaver SC. Lifetime rates of suicide attempts among subjects with bipolar and unipolar disorders relative to subjects with other Axis I disorders. Biol Psychiatry 1996;39(10):896-899

4 Latalova K, Kamaradova D, Prasko J. Suicide in bipolar disorder: a review. Psychiatr Danub 2014;26(2):108-114

5 van Heeringen K, Mann JJ. The neurobiology of suicide. Lancet Psychiatry 2014;1(1):63-72

6 O'Connor RC, Nock MK. The psychology of suicidal behaviour. Lancet Psychiatry 2014;1(1):73-85

7 Hawton K, van Heeringen K. Suicide. Lancet 2009;373 (9672):1372-1381

8 Mann JJ. Neurobiology of suicidal behaviour. Nat Rev Neurosci 2003;4(10):819-828

9 Caspi A, Sugden K, Moffitt TE, et al. Influence of life stress on depression: moderation by a polymorphism in the 5-HTT gene. Science 2003;301(5631):386-389

10 Roy-Byrne PP, Post RM, Hambrick DD, Leverich GS, Rosoff AS. Suicide and course of illness in major affective disorder. J Affect Disord 1988;15(1):1-8

11 Schaffer A, Isometsä ET, Tondo L, et al. International Society for Bipolar Disorders Task Force on Suicide: meta-analyses and meta-regression of correlates of suicide attempts and suicide deaths in bipolar disorder. Bipolar Disord 2015;17(1):1-16

12 Tidemalm D, Haglund A, Karanti A, Landén M, Runeson B. Attempted suicide in bipolar disorder: risk factors in a cohort of 6086 patients. PLoS One 2014;9(4):e94097

13 Fagiolini A, Kupfer DJ, Rucci P, Scott JA, Novick DM, Frank E. Suicide attempts and ideation in patients with bipolar I disorder. J Clin Psychiatry 2004;65(4):509-514

14 Finseth PI, Morken G, Andreassen OA, Malt UF, Vaaler AE. Risk factors related to lifetime suicide attempts in acutely admitted bipolar disorder inpatients. Bipolar Disord 2012;14(7):727-734

15 Azorin J-M, Kaladjian A, Adida M, et al. Risk factors associated with lifetime suicide attempts in bipolar I patients: findings from a French National Cohort. Compr Psychiatry 2009;50(2):115-120

16 Erić AP, Erić I, Ćurković M, et al. The temperament and character traits in patients with major depressive disorder and bipolar affective disorder with and without suicide attempt. Psychiatr Danub 2017;29(2):171-178

17 Liu S-I, Huang Y-H, Wu Y-H, et al. Temperament traits in suicidal and non-suicidal mood disorder patients in Taiwan. Psychiatry Res 2017;253:260-266

18 Pawlak J, Dmitrzak-Węglarz M, Skibińska M, et al. Suicide attempts and psychological risk factors in patients with bipolar and unipolar affective disorder. Gen Hosp Psychiatry 2013;35(3):309-313

19 Perroud N, Baud P, Ardu S, et al. Temperament personality profiles in suicidal behaviour: an investigation of associated demographic, clinical and genetic factors. J Affect Disord 2013;146(2):246-253

20 Sarısoy G, Kaçar OF, Pazvantoğlu O, et al. Temperament and character traits in patients with bipolar disorder and associations with attempted suicide. Compr Psychiatry 2012;53(8):1096-1102

21 Garno JL, Goldberg JF, Ramirez PM, Ritzler BA. Bipolar disorder with comorbid cluster B personality disorder features: impact on suicidality. J Clin Psychiatry 2005;66(3):339-345 
22 Swann AC, Lijffijt M, Lane SD, Steinberg JL, Moeller FG. Increased trait-like impulsivity and course of illness in bipolar disorder. Bipolar Disord 2009;11(3):280-288

23 Wang L, He CZ, Yu YM, et al. Associations between impulsivity, aggression, and suicide in Chinese college students. BMC Public Health 2014;14:551

24 Pallaskorpi S, Suominen K, Ketokivi M, et al. Incidence and predictors of suicide attempts in bipolar I and II disorders: a 5-year follow-up study. Bipolar Disord 2017;19(1):13-22

25 Pawlak J, Dmitrzak-Węglarz M, Maciukiewicz M, et al. Personality traits as an endophenotype in genetic studies on suicidality in bipolar disorder. Acta Neuropsychiatr 2017;29(2):115-121

26 Akbari M, Haghdoost AA, Nakhaee N, Bahramnejad A, Baneshi MR, Zolala F. Risk and protective factor for suicide attempt in Iran: a matched case-control study. Arch Iran Med 2015;18(11):747-752

27 Li X-B, Liu J-T, Zhu X-Z, Zhang L, Tang Y-L, Wang C-Y. Childhood trauma associates with clinical features of bipolar disorder in a sample of Chinese patients. J Affect Disord 2014;168:58-63

28 Jordans MJD, Kaufman A, Brenman NF, et al. Suicide in South Asia: a scoping review. BMC Psychiatry 2014;14:358

29 Knipe D, Williams AJ, Hannam-Swain S, et al. Psychiatric morbidity and suicidal behaviour in low- and middle-income countries: a systematic review and meta-analysis. PLoS Med 2019;16(10):e1002905

30 Ahmed HU, Hossain MD, Aftab A, et al. Suicide and depression in the World Health Organization South-East Asia Region: a systematic review. WHO South-East Asia J Public Health 2017;6(1):60-66

31 Gandhi A, Luyckx K, Maitra S, Claes L. Non-suicidal self-injury and other self-directed violent behaviors in India: a review of definitions and research. Asian J Psychiatr 2016;22:196-201

32 Rane A, Nadkarni A. Suicide in India: a systematic review. Shanghai Jingshen Yixue 2014;26(2):69-80

33 Mythri SV, Ebenezer JA. Suicide in India: distinct epidemiological patterns and implications. Indian J Psychol Med 2016;38(6):493-498

34 Slama F, Bellivier F, Henry C, et al. Bipolar patients with suicidal behavior: toward the identification of a clinical subgroup. J Clin Psychiatry 2004;65(8):1035-1039

35 Sheehan DV, Lecrubier Y, Sheehan KH, et al. The MiniInternational Neuropsychiatric Interview (M.I.N.I.): the development and validation of a structured diagnostic psychiatric interview for DSM-IV and ICD-10. J Clin Psychiatry 1998;59(Suppl 20) :22-33, quiz 34-57

36 Hamilton M. A rating scale for depression. J Neurol Neurosurg Psychiatry 1960;23(1):56-62

37 Young RC, Biggs JT, Ziegler VE, Meyer DA. A rating scale for mania: reliability, validity and sensitivity. $\mathrm{Br} \mathrm{J}$ Psychiatry 1978;133(5):429-435

38 Roy-Byrne P, Post RM, Uhde TW, Porcu T, Davis D. The longitudinal course of recurrent affective illness: life chart data from research patients at the NIMH. Acta Psychiatr Scand Suppl 1985;317:1-34

39 Singh G, Kaur D, Kaur H. Presumptive stressful life events scale (psles) - a new stressful life events scale for use in India. Indian J Psychiatry 1984;26(2):107-114

40 Addison CC, Campbell-Jenkins BW, Sarpong DF, et al. Psychometric evaluation of a Coping Strategies Inventory Short-Form (CSI-SF) in the Jackson Heart Study cohort. Int J Environ Res Public Health 2007;4(4):289-295

41 Beck AT, Weissman A, Lester D, Trexler L. The measurement of pessimism: the hopelessness scale. J Consult Clin Psychol 1974;42(6):861-865

42 Plutchik R, van Praag HM. A self-report measure of violence risk, II. Compr Psychiatry 1990;31(5):450-456
43 Bryant FB, Smith BD. Refining the architecture of aggression: a measurement model for the Buss-Perry aggression questionnaire. J Res Pers 2001;35:138-167

44 Patton JH, Stanford MS, Barratt ES. Factor structure of the Barratt impulsiveness scale.J Clin Psychol 1995;51(6):768-774

45 Hall RC. Global Assessment of Functioning. A modified scale. Psychosomatics 1995;36(3):267-275

46 Goldstein TR, Ha W, Axelson DA, et al. Predictors of prospectively examined suicide attempts among youth with bipolar disorder. Arch Gen Psychiatry 2012;69(11):1113-1122

47 López P, Mosquera F, de León J, et al. Suicide attempts in bipolar patients. J Clin Psychiatry 2001;62(12):963-966

48 Song JY, Yu HY, Kim SH, et al. Assessment of risk factors related to suicide attempts in patients with bipolar disorder. J Nerv Ment Dis 2012;200(11):978-984

49 Kattimani S, Subramanian K, Sarkar S, Rajkumar RP, Balasubramanian S. History of lifetime suicide attempt in bipolar I disorder: its correlates and effect on illness course. Int J Psychiatry Clin Pract 2017;21(2):118-124

50 Umamaheswari V, Avasthi A, Grover S. Risk factors for suicidal ideations in patients with bipolar disorder. Bipolar Disord 2014;16(6):642-651

51 Pawlak J, Dmitrzak-Węglarz M, Skibińska M, et al. Suicide attempts and clinical risk factors in patients with bipolar and unipolar affective disorders. Gen Hosp Psychiatry 2013;35(4):427-432

52 Perroud N, Baud P, Mouthon D, Courtet P, Malafosse A. Impulsivity, aggression and suicidal behavior in unipolar and bipolar disorders. J Affect Disord 2011;134(1-3):112-118

53 Giegling I, Olgiati P, Hartmann AM, et al. Personality and attempted suicide. Analysis of anger, aggression and impulsivity. J Psychiatr Res 2009;43(16):1262-1271

54 Oquendo MA, Waternaux C, Brodsky B, et al. Suicidal behavior in bipolar mood disorder: clinical characteristics of attempters and nonattempters. J Affect Disord 2000;59(2):107-117

55 Dervic K, Carballo JJ, Baca-Garcia E, et al. Moral or religious objections to suicide may protect against suicidal behavior in bipolar disorder. J Clin Psychiatry 2011;72(10):1390-1396

56 MacPherson HA, Weinstein SM, West AE. Non-suicidal self-injury in pediatric bipolar disorder: clinical correlates and impact on psychosocial treatment outcomes. J Abnorm Child Psychol 2018;46(4):857-870

57 D'Anci KE, Uhl S, Giradi G, Martin C. Treatments for the prevention and management of suicide: a systematic review. Ann Intern Med 2019;171(5):334-342

58 Ougrin D, Tranah T, Stahl D, Moran P, Asarnow JR. Therapeutic interventions for suicide attempts and self-harm in adolescents: systematic review and meta-analysis. J Am Acad Child Adolesc Psychiatry 2015;54(2):97-107.e2

59 Raj S, Sachdeva SA, Jha R, et al. Effectiveness of mindfulness based cognitive behavior therapy on life satisfaction, and life orientation of adolescents with depression and suicidal ideation. Asian J Psychiatr 2019;39:58-62

60 Gøtzsche PC, Gøtzsche PK. Cognitive behavioural therapy halves the risk of repeated suicide attempts: systematic review. J R Soc Med 2017;110(10):404-410

61 Turner BJ, Austin SB, Chapman AL. Treating nonsuicidal selfinjury: a systematic review of psychological and pharmacological interventions. Can J Psychiatry 2014;59(11):576-585

62 Meerwijk EL, Parekh A, Oquendo MA, Allen IE, Franck LS, Lee KA. Direct versus indirect psychosocial and behavioural interventions to prevent suicide and suicide attempts: a systematic review and meta-analysis. Lancet Psychiatry 2016;3(6):544-554

63 Vijayakumar L. hallenges and opportunities in suicide prevention in South-East Asia. WHO South-East Asia J Public Health. 2017;6(1):30-33 